\title{
Geoscięnces
}

http://dx.doi.org/10.1590/0370-44672017720154

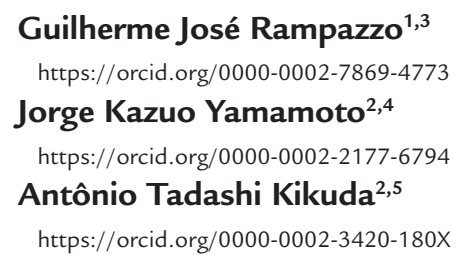

${ }^{1}$ Universidade de São Paulo - USP, Instituto de Geociências, Programa de Pós-Graduação em Recursos Minerais e Hidrogeologia, São Paulo - São Paulo - Brasil.

${ }^{2}$ Universidade de São Paulo - USP, Instituto de Geociências, Departamento de Geologia Sedimentar e Ambiental, São Paulo - São Paulo - Brasil.

E-mails: 3ggr@pocos-net.com.br, grampazzo@usp.br, 4jkyamamo@usp.br, ${ }^{5}$ lig@usp.br

\section{Quantifying mean grades and uncertainties from the ratio of service variables: accumulation to thickness. Applied to a phosphate deposit in Southern Mato Grosso, Brazil}

\begin{abstract}
Estimating mineral resources of a stratiform mineral deposit is not always a simple activity. Some difficulties can arise in mineral deposits where the thickness is relatively much smaller than the dimensions in the horizontal plane, or because these deposits have suffered events after their genesis, such as thrusts and folds. Usually, in these cases, we use a new variable named accumulation as a product between the average grade and thickness. Then, from these service variables, accumulation and thickness are estimated in a regular grid. Dividing accumulation by thickness, we have the mean grade. However, the mean grade is just an approach because the uncertainties of variables are not considered in this division. This calls for applying the Taylor series to computing, not only the mean grade, but also the associated uncertainty. In this article, we present the satisfactory results of this method applied to quantify the mean grades and uncertainties of the blocks to a stratiform phosphate deposit located in southern Mato Grosso, Brazil.
\end{abstract}

Keywords: Taylor Series, geostatistic, uncertainty, service variable, mean grade, phosphaste.

\section{Introduction}

A variable named accumulation is commonly used for ore resource estimation in stratiform, stratabound, or tabular deposits. This variable is also known as the service variable (Rossi and Deutsch, 2014) and is defined as the product of the average grade in the borehole and the thickness of the mineralized section (Journel and Huijbregts, 1978; Chilès and Delfiner, 2012). Actually, this variable has been used in the valuation of gold mines and it represents direct measurements of gold per unit area (Krige, 1978). The mean grade of a block is computed by dividing the estimated accumulation by the estimated thickness (David, 1977; Dowd and Milton, 1987; Rossi and
Deutsch, 2014). However, the resulting mean grade is just an approximation (Dowd and Milton, 1987, p. 42) because the quotient is a function defined by the ratio of accumulation to thickness. The uncertainty associated with the mean grade must take into consideration uncertainties regarding estimations of both accumulation and thickness. Actually, we want to know the probability distribution function of the mean grade resulting from the division of accumulation by thickness. This issue can be addressed by Monte Carlo simulation, but the main drawback of this method is that the results obtained are not readily transferable to a new situation due to the nature of this method; it does not provide a closed analytical form (Dettinger and Wilson, 1981). On the other hand, there is another approach that allows calculating the statistical moments of the mean grade distribution, which is known as the first and second moment method (Dettinger and Wilson, 1981).

This approach is based on second order Taylor Series expansion of the ratio function (accumulation by thickness). The mean grade and its variance can be calculated by mathematical expressions. Herein, the equations developed for the calculation of mean grade and variance by Yamamoto et al. (2018) are tested in a real database of research in a stratiform phosphate mineral deposit located in the southern state of Mato Grosso. 


\section{Review of previous studies}

It is clear in previous studies that the average grade resulting from the division of estimated accumulation by estimated thickness is accepted as estimated grade (David, 1977; Krige, 1978; Journel and Hujbregts,

$$
G^{*}=\frac{G T^{*}}{T^{*}}
$$

For notational convenience we will consider hereafter the function grade as:

$$
G=f(x, y)=\frac{X}{Y}
$$

However, according to Dowd and Milton (1987), the average grade obtained by dividing estimated accumulation by estimated thickness is just an approximation and that it is valid only under restrictive conditions: accurate thickness estimates; use of paired data to estimate both accumulation and thickness. Herein, we provide a full equation to calculate the average grade.

For the average grade, we have to assess the uncertainty associated with the estimate. Previous studies have addressed this issue by assuming that true values are known at estimation locations (Journel and Huijbregts, 1978). There-
1978; Sinclair and Blackwell, 2002; Chilès and Delfiner, 2012; Rossi and Deutsch, 2014).

$$
\varepsilon_{x}=X^{*}-X \quad \varepsilon_{y}=Y^{*}-Y \quad \varepsilon_{G}=G^{*}-G
$$

Since estimates are assumed to be unbiased, we have (Journel and Huijbregts, 1978):

$$
E\left[\varepsilon_{x}\right]=0 \quad E\left[\varepsilon_{y}\right]=0
$$

According to these authors, estimation variances are also known:

$$
\sigma_{x}^{2}=E\left[\varepsilon_{x}^{2}\right] \quad \sigma_{y}^{2}=E\left[\varepsilon_{y}^{2}\right]
$$

The relative estimation variance of the quotient $G=X / Y$ can be calculated as

This equation has also been used by Dowd and Milton (1987) and by Sinclair and Blackwell (2002). second order Taylor expansion (Journel and Huijbregts, 1978):

$$
\frac{\sigma_{G}^{2}}{G^{2}}=\frac{\sigma_{X}^{2}}{X^{2}}+\frac{\sigma_{Y}^{2}}{Y^{2}}-2 \rho_{X Y} \frac{\sigma_{X}}{X} \frac{\sigma_{Y}}{Y}
$$

Expression (2) considers that all variables are roughly lognormally distributed and therefore it is considered fore, errors can be determined and the error of the average grade results from the propagation of errors of accumulation and thickness. The true global values $\mathrm{G}, \mathrm{X}$ and $\mathrm{Y}$ are known and also the estimated values $G^{*}, X^{*}$ and $Y^{*}$ (Journel and Huijbregts, 1978). Thus, we can derive error expressions:

$$
\operatorname{Var}[G]=\left(\frac{d G}{d X}\right)^{2} \operatorname{Var}[X]+\left(\frac{d G}{d Y}\right)^{2} \operatorname{Var}[Y]+2\left(\frac{d G}{d X}\right)\left(\frac{d G}{d Y}\right) \operatorname{cov}(X, Y)
$$

Notice that Equation (3) is the formula for variance of function $G$ that resulted from first order Taylor expansion.

The derivatives of the function

$$
\frac{d G}{d X}=\frac{1}{y} \frac{d G}{d Y}=\frac{1}{y^{2}}
$$

a particular case of Tukey's formula (David, 1977):

Replacing these derivatives in (3) and considering the variance around a point $\theta=\left(\mu_{x}, \mu_{y}\right)$, we have:

$$
\operatorname{Var}[G]=\frac{\sigma_{x}^{2}}{\mu_{y}^{2}}+\frac{\mu_{x}^{2} \sigma_{y}^{2}}{\mu_{y}^{4}}-2 \frac{\mu_{x} \operatorname{Cov}(X, Y)}{\mu_{y}^{3}}
$$

Although equations (2) and (4) look different, we can show that Equa- tion (2) was also derived from (3) as follows. Multiplying both sides of Equa- tion (2) by $G^{2}=X^{2} / Y^{2}$ and knowing that $\operatorname{Cov}(X, Y)=\rho_{x y} \sigma_{x} \sigma_{y}$, we have: 
$\sigma_{G}^{2}=\frac{\sigma_{x}^{2}}{Y^{2}}+X^{2} \frac{\sigma_{y}^{2}}{Y^{4}}-2 \frac{X \operatorname{Cov}(X, Y)}{Y^{3}}$

Since Equation (2) results from first order Taylor expansion and considering

that the expansion is made about a point $\theta=\left(\mu_{x^{\prime}} \mu_{y}\right)$, we can replace $X$ and $Y$ by

$\sigma_{G}^{2}=\frac{\sigma_{x}^{2}}{\mu_{y}^{2}}+\frac{\mu_{x}^{2} \sigma_{y}^{2}}{\mu_{y}^{4}}-2 \frac{\mu_{x} \operatorname{Cov}(X, Y)}{\mu_{y}^{3}}$

Actually, this is an advantage of the Taylor method because it allows

computation of the variance of the function without knowing the shapes $\mu_{x}$ and $\mu_{y}$, respectively. Thus, we have the same equation as (4):

\subsection{Computing mean and variance from second order taylor expansion}

Yamamoto et al. (2018) developed mathematical expressions for calculating mean and variance for arithmetically combined variables. For the ratio function the mean or the mathematical expectation around a of input distributions (Maskey and Guinot, 2003).

$$
\left.\begin{array}{c}
E[f(x, y)] \approx \frac{\mu_{x}}{\mu_{y}}-\frac{\sigma_{x y}}{\mu_{y}^{2}}+\frac{\mu_{x} \sigma_{y}^{2}}{\mu_{y}^{3}} \\
\operatorname{Var}[f(x, y)] \approx \\
+\frac{\sigma_{x}^{2}}{\mu_{y}^{2}}+\frac{\mu_{x}^{2}}{\mu_{y}^{4}} \sigma_{y}^{2}-2 \frac{\mu_{x}}{\mu_{y}^{3}} \sigma_{x y}+\frac{1}{\mu_{y}^{4}} E\left[\left(\sigma_{x y}-\left(x-\mu_{x}\right)\left(y-\mu_{y}\right)\right)^{2}\right]+\frac{\mu_{x}^{2}}{\mu_{y}^{6}} E\left[\left(\left(y-\mu_{y}\right)^{2}-\sigma_{y}^{2}\right)^{2}\right] \\
+\frac{2}{\mu_{y}^{3}} E\left[\left(x-\mu_{x}\right)\left[\sigma_{x y}-\left(x-\mu_{x}\right)\left(y-\mu_{y}\right)\right]\right]+2 \frac{\mu_{x}}{\mu_{y}^{4}} E\left[\left(x-\mu_{x}\right)\left[\left(y-\mu_{y}\right)^{2}-\sigma_{y}^{2}\right]\right] \\
+2 \frac{\mu_{x}}{\mu_{y}^{4}} E\left[\left(y-\mu_{y}\right)\left[\sigma_{x y}-\left(x-\mu_{x}\right)\left(y-\mu_{y}\right)\right]\right]-2 \frac{\mu_{x}^{2}}{\mu_{y}^{5}} E\left[\left(y-\mu_{y}\right)\left[\left(y-\mu_{y}\right)^{2}-\sigma_{y}^{2}\right]\right] \\
+2 \frac{\mu_{x}}{\mu_{y}^{5}} E\left[\left[\sigma_{x y}-\left(x-\mu_{x}\right)\left(y-\mu_{y}\right)\right]\left[\left(y-\mu_{y}\right)^{2}-\sigma_{y}^{2}\right]\right]
\end{array}\right\}
$$

point $\theta=\left(\mu_{x^{\prime}} \mu_{y}\right)$ and the variance are calculated as:
Where $\sigma_{x y}$ is the covariance between $\mathrm{x}$ and y. Details of the mathematical development of Equations (5) and (6) can be found in Yamamoto et al. (2018).

Notice that Equation (5) is just an approach based on second order Taylor expansion. As shown in a previous item, the mean grade is usually calculated as the ratio of accumulation to thickness. Actually, keeping just the first term on the right side of Equation (5), means that we are calculating the mathematical expectation after the first order Taylor expansion. This is why Dowd and Milton (1987) drew attention to this approach. Evidently, Equation (5), which results from second order Taylor expansion is better than considering just the first order. Moreover, Equation (5) is still an approach because there is no exact formula for the mean of the ratio of $x$ to $y$, since the function $f(x, y)=x / y$ is infinitely differentiable with respect to y. Yamamoto et al. (2018) also provided a formula for the mean after the third order Taylor expansion.

Equation (6) is composed of ten terms as a result from second order Taylor expansion for the variance of the function $f(x, y)=x / y$. The first three terms on the right side of Equation (6) are related to the first order expansion (equation 4). Yamamoto et al. (2018) showed that this equation is a much better approach than just keeping the first order terms.

Mean and variance after Equations (5) and (6), respectively, are valid as global statistics. Since we are interested in computing mineral resources in blocks of a $2 \mathrm{D}$ deposit, we must be able to compute local first and second order statistical moments (mean, variance and covariance) and highorder moments as required by Equation (6).

Because accumulation and thick-

$$
\begin{gathered}
\mu_{x} \Leftarrow G T^{*}\left(x_{o}\right)=\sum_{i=1}^{n} \lambda_{i} G T\left(x_{i}\right) \\
\mu_{y} \Leftarrow T^{*}\left(x_{o}\right)=\sum_{i=1}^{n} \lambda_{i} T\left(x_{i}\right)
\end{gathered}
$$

ness are additive variables, they can be estimated by kriging (Chilès and Delfiner, 2012). Theoretically, $\mu_{x}$ and $\mu_{y}$ are estimated separately from different sets of kriging weights. However, we cannot proceed with further calculations, especially second order moments, because of the risk of bias, as recognized by Chilès and Delfiner (2012). These authors suggest using the same basic variogram multiplied by a constant. Actually, accumulation and thickness are proportional variables and therefore their variograms are proportional to the same basic variogram function (Chilès and Delfiner, 2012). Indeed, these variables are intrinsically co-regionalized (Journel and Huijbregts, 1978). Considering that both variables are estimated using the same data configuration, the kriging weights will be the same (Chilès and Delfiner, 2012) $\mu_{x}$ and $\mu_{y}$ are calculated as follows: 
The variances $\sigma_{x}^{2}$ and $\sigma_{y}^{2}$ are calculated by using the approach pro- vided by the interpolation variance

(Yamamoto, 2000).

$$
\begin{gathered}
\sigma_{x}^{2} \Leftarrow S_{G T}^{2}\left(x_{o}\right)=\sum_{i=1}^{n} \lambda_{i}\left(G T\left(x_{i}\right)-G T^{*}\left(x_{o}\right)\right)^{2} \\
\sigma_{y}^{2} \Leftarrow S_{T}^{2}\left(x_{o}\right)=\sum_{i=1}^{n} \lambda_{i}\left(T\left(x_{i}\right)-T^{*}\left(x_{o}\right)\right)^{2}
\end{gathered}
$$

The covariance between accumulation and thickness can be computed as (Yamamoto et al. 2018):

$$
\sigma_{x y} \Leftarrow \operatorname{Cov}(G T, T)=\sum_{i=1}^{n} \lambda_{i} G T\left(x_{i}\right) T\left(x_{i}\right)-\left(\sum_{i=1}^{n} \lambda_{i} G T\left(x_{i}\right)\right)\left(\sum_{i=1}^{n} \lambda_{i} T\left(x_{i}\right)\right)
$$

First and second order statistical moments are used to compute

\section{Materials and methods}

For this research, we used a geochemical database composed of 92 drillholes, which were sampled at one-meter intervals and generated 4,892 samples. The evaluation method proposed by this article required careful analysis of each drillhole for the selection of mineralized intervals in apatite phosphorus (considering the $\mathrm{CaO} / \mathrm{P}_{2} \mathrm{O}_{5}$ ratio) and the insertion of some variables into the database: weighted mean of $\mathrm{P}_{2} \mathrm{O}_{5}$, thickness and accumulation.

Accumulation of $\mathrm{P}_{2} \mathrm{O}_{5}$ content by thickness resulted in 92 sample points,

\section{Results and discussion}

Analyzing frequency distributions for both variables, we conclude that they present positive asymmetry

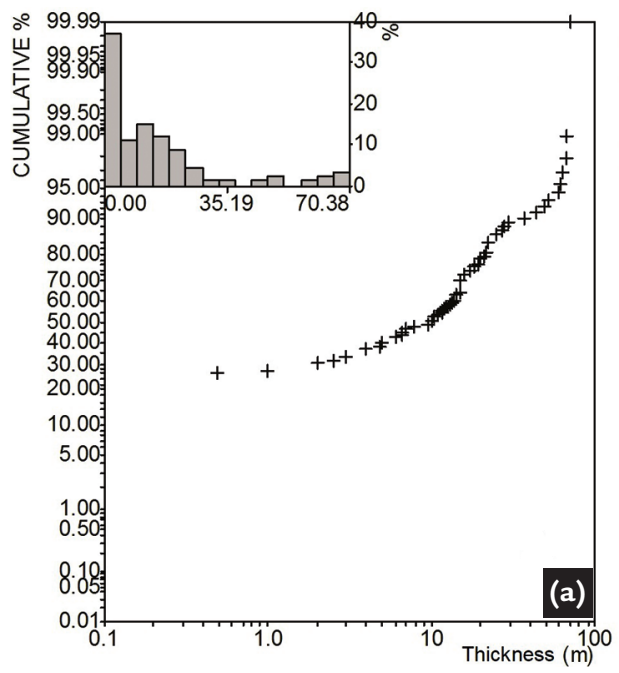

both mean and variances according to Equations (5) and (6), respectively.

$$
E[.]=\sum_{i=1}^{n} w_{i}(.)
$$

which the samples generated consider only $\mathrm{x}$ and $\mathrm{y}$ coordinates, not considering the $\mathrm{z}$ coordinate and placing all samples in a single horizontal plane.

Evaluation of mineral resources using a service variable makes use of some additional procedures. Thus, after adding these variables to the database, some tasks are required to obtain the mean grade and its variance of estimated blocks, such as statistical analysis of variable thickness and accumulation; calculation of experimental variograms of both variables and determina-
High-order moments are calculated as: tion of directions of anisotropy; modeling an experimental variogram; ordinary kriging of both variables; calculation of the mean grade and uncertainty; displaying 2D maps of the mean grade and uncertainty.

It should be pointed out that ordinary kriging was applied because it is the best non-biased linear estimator, besides being able to calculate a local kriging variance and covariance through the equations by Yamamoto (2000), and of great importance for the calculation of uncertainty by the equations presented here deriving the Taylor Series.
(Figure 1). Moreover, we can see that a quarter of the distribution has zeroes, because of negative drillholes

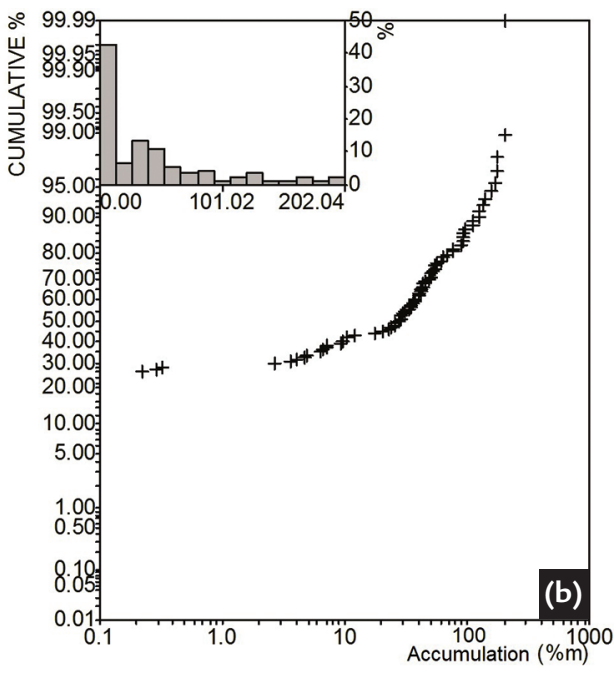

(no phosphate apatite). Statistics for both variables are presented in Tables 1 and 2 .
Figure 1

Accumulated frequency curve of the Thickness (a) and Accumulation (b) variables with histogram inserted. 
Thickness Variable (m)

Table 1 Statistics for thickness.

Table 2 Statistics for accumulation.

In order to identify the directions of anisotropy, we computed the variogram

Figure 2

Variogram maps for Thickness (a) and Accumulation (b) variables.

Experimental variograms (Figure 3) were computed according to anisotropic di-

Figure 3

Experimental variograms for Thickness (a) and Accumulation (b) variables. Spherical theoretical model fit.

Table 3

Variogram parameters of Thickness variable (a).

Table 4

Variogram parameters of Accumulation variable (b).

In Figure 3, it is possible to check the proportionality of the variograms by a constant $\mathrm{k}$, according to Chilès and Delfiner (2012) who assert that proportional variables must have proportional variograms for the same basic variogram function.

\begin{tabular}{c|c|c|c|c|c|c|c|c}
\hline $\begin{array}{c}\# \\
\text { data }\end{array}$ & $\begin{array}{c}\text { Mean } \\
(\mathrm{m})\end{array}$ & $\begin{array}{c}\text { Standard } \\
\text { Deviation }\end{array}$ & $\begin{array}{c}\text { Coefficient } \\
\text { of Variation }\end{array}$ & Maximum & Minimum & $\begin{array}{c}\text { Upper } \\
\text { Quartile }\end{array}$ & Median & $\begin{array}{c}\text { Lower } \\
\text { Quartile }\end{array}$ \\
\hline 92 & 14.12 & 17.23 & 1.22 & 70.30 & 0.00 & 18.00 & 9.74 & -99.00 \\
\hline
\end{tabular}

Accumulation Variable ( $\mathrm{m} \%)$

\begin{tabular}{c|c|c|c|c|c|c|c|c}
\hline $\begin{array}{c}\# \\
\text { data }\end{array}$ & $\begin{array}{c}\text { Mean } \\
(\% \mathrm{~m})\end{array}$ & $\begin{array}{c}\text { Standard } \\
\text { Deviation }\end{array}$ & $\begin{array}{c}\text { Coefficient } \\
\text { of Variation }\end{array}$ & Maximum & Minimum & $\begin{array}{c}\text { Upper } \\
\text { Quartile }\end{array}$ & Median & $\begin{array}{c}\text { Lower } \\
\text { Quartile }\end{array}$ \\
\hline 92 & 42.06 & 50.82 & 1.21 & 202.04 & 0.00 & 54.67 & 28.05 & -99.00 \\
\hline
\end{tabular}

map (Figure 2), which shows anisotropic directions between $70-80^{\circ}$ and $160-170^{\circ}$ in which the former is the direction of high continuity, showing lower variance.

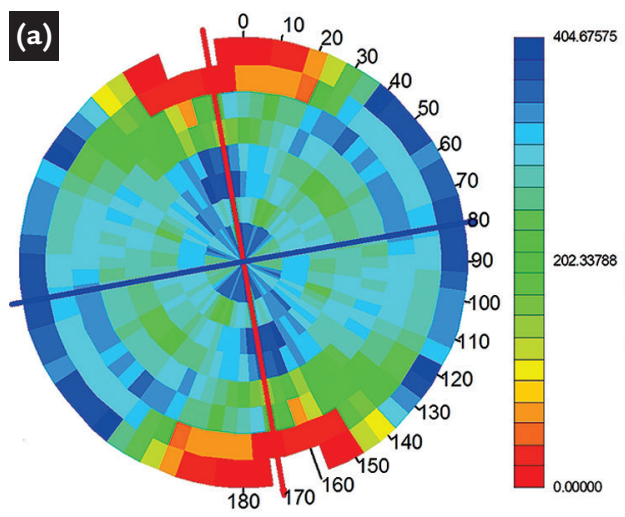

rections as displayed in variogram maps. In addition, Figure 3 shows variogram models

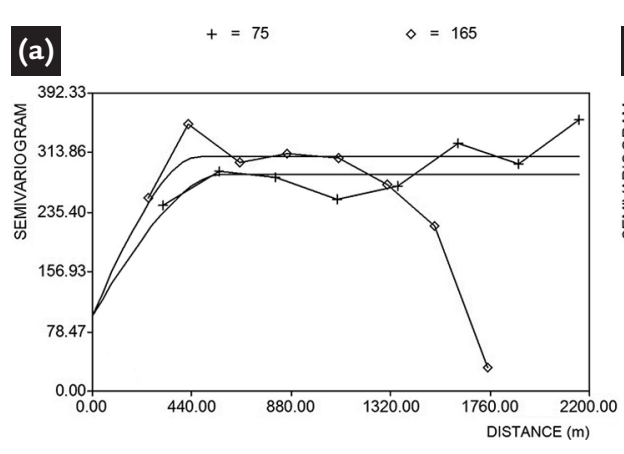

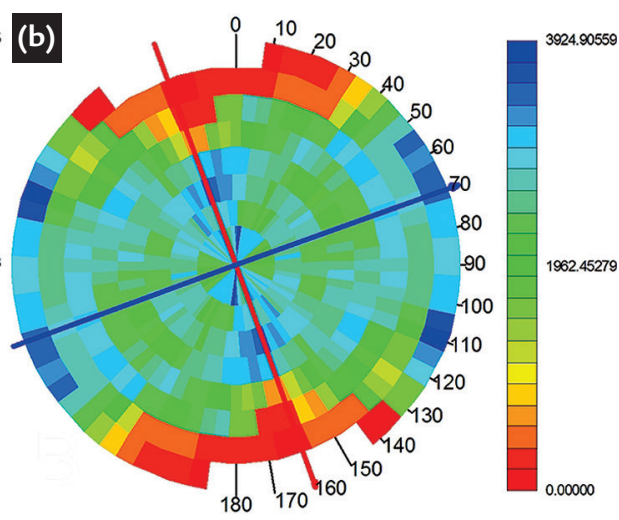

fitted to experimental variograms according to parameters presented in Tables 3 and 4.

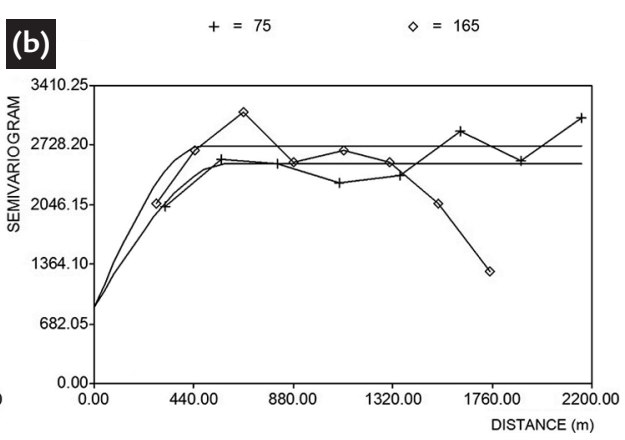

Thickness Variable

\begin{tabular}{|c|c|c|c|c|c|c|c|c|}
\hline $\begin{array}{c}\text { Nugget } \\
\text { Effect }\end{array}$ & \multirow{2}{*}{$\begin{array}{c}\text { Struct. } 1 \\
\left(75^{\circ}\right)\end{array}$} & $\begin{array}{c}\text { Range } \\
\text { max. }\end{array}$ & $\begin{array}{c}\text { Range } \\
\text { min. }\end{array}$ & Sill & \multirow{2}{*}{$\begin{array}{c}\text { Struct. } 2 \\
\left(165^{\circ}\right)\end{array}$} & $\begin{array}{c}\text { Range } \\
\text { max. }\end{array}$ & $\begin{array}{c}\text { Range } \\
\text { min. }\end{array}$ & Sill \\
\hline 100 & & 585 & 480 & 285 & & $1 * 10^{30}$ & 480 & 309 \\
\hline
\end{tabular}

Accumulation Variable

\begin{tabular}{c|c|c|c|c|c|c|c|c}
\hline $\begin{array}{c}\text { Nugget } \\
\text { Effect }\end{array}$ & \multirow{2}{*}{$\begin{array}{c}\text { Struct. } 1 \\
\left(75^{\circ}\right)\end{array}$} & $\begin{array}{c}\text { Range } \\
\text { max. }\end{array}$ & $\begin{array}{c}\text { Range } \\
\text { min. }\end{array}$ & Sill & & $\begin{array}{c}\text { Range } \\
\text { max. }\end{array}$ & $\begin{array}{c}\text { Range } \\
\text { min. }\end{array}$ & Sill \\
\cline { 1 - 1 } & & 585 & 480 & 2508 & $\left(165^{\circ}\right)$ & $1 * 10^{30}$ & 480 & 2719.2 \\
\hline
\end{tabular}

Then, ordinary block kriging was carried out based on the variogram models presented. The block size for both directions is equal to 50 meters, resulting in 2,931 blocks. The blocks are defined in order to generate blocks with minerable dimensions, since the average distance of the samples is very large and would generate non-operational blocks. Values of local variances and covariances were computed after expressions 9, 10 and 11, which were replaced in Equations 5 and 6 for calculation of the mean grade of $\mathrm{P}_{2} \mathrm{O}_{5}$ and associated 
uncertainty with the estimated blocks.

The results of this calculation can be displayed in 2D maps, as shown in

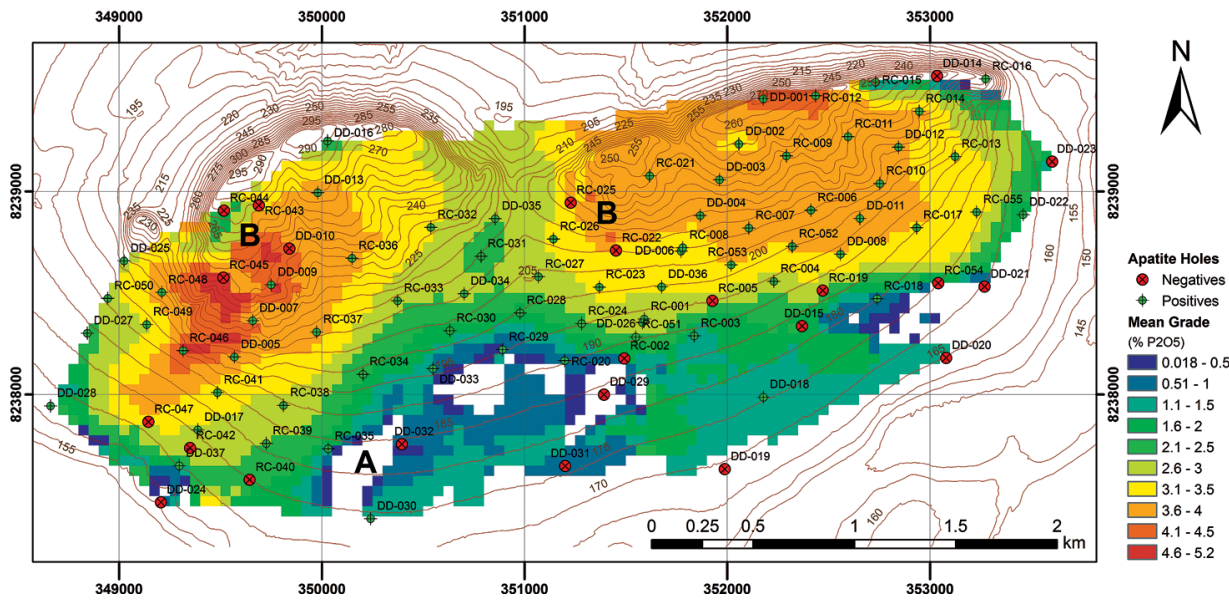

In Figure 4, there are empty blocks highlighted by the letter A. Actually, empty blocks resulted from negative mean grades because Equation 5 takes into account a subtraction of the second

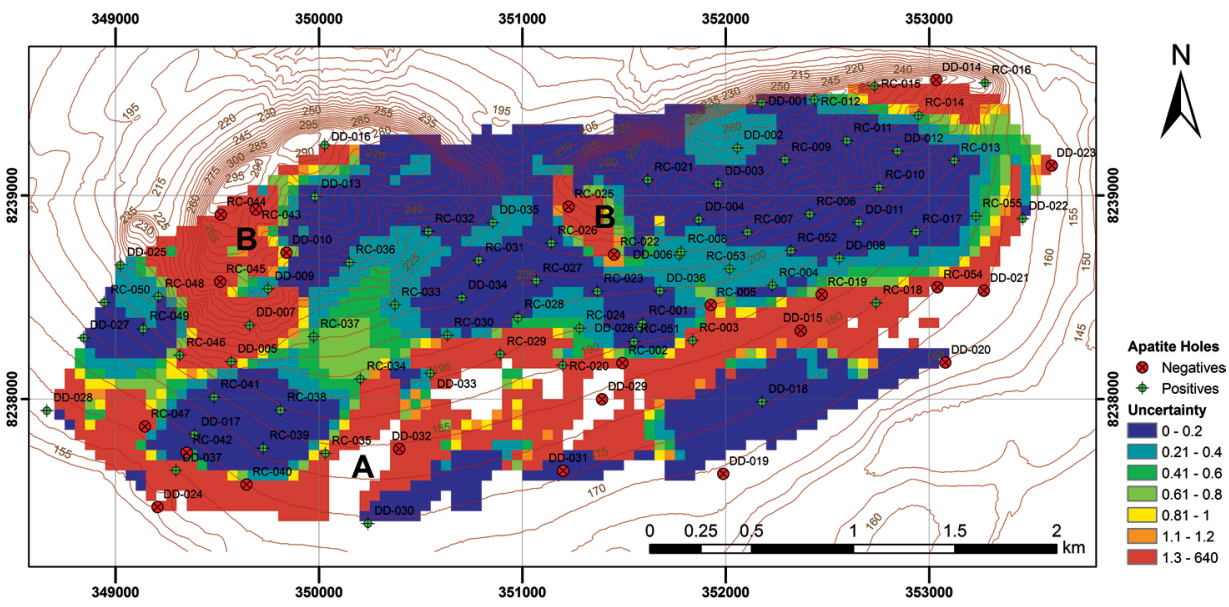

A notable result can be seen in Figure 5, in which high uncertainties are associated with lithological boundaries.

\section{Conclusion}

This article provides an efficient method to compute not only the average grade from the ratio between accumulation and thickness, but also its uncertainty. Therefore, it represents a solution to the issue discussed in literature, which states that the ratio of accumulation to thickness

\section{Acknowledgments}

We are very grateful to BEMISA - Brasil Exploração Mineral S.A - for
Figures 4 and 5, for the mean grade of $\mathrm{P}_{2} \mathrm{O}_{5}$ and associated uncertainty, respectively. Remembering that dimension $\mathrm{z}$

term that is greater than the first term. On the other hand, the letter B indicates regions of high grades but closer to negative drillholes. This happens because the thickness $\left(T^{*}=\mu_{y}\right)$ is much
$B$ show high uncertainties associated with high mean grades. This means that these is just an approach. It is important to note that the solution presented was possible because of the computation of local variances and co-variances. Finally, the application of the proposed method in a real database was able to show the efficiency of the service variable method and its use releasing the data used in this paper and to CAPES for the funding the is disregarded when the average hole content is accumulated by multiplying it to the thickness.
Figure 4

Map of mean grade of $\mathrm{P}_{2} \mathrm{O}_{5}$.

less than the estimated accumulation $\left(G T^{*}=\mu_{x}\right)$. Then in these cases care must be taken in interpreting the results, especially for high grades in regions of low probability.
Figure 5

Map of uncertainties

associated with the estimates.

high mean grades are meaningless and should be disregarded when calculating the mineral resource.

for ore resource estimation in stratiform deposits, obtaining fitting results with the drillholes and the mineralization, as well as solving the problem of the measurement of the local uncertainty associated with the estimates of grades.

scholarship of the first author. 


\section{References}

CHILÈS, J. P., DELFINER, P. Geostatistic: modeling special uncertainty. (2.nd.). edition. Hoboken: Wiley, 2012. 699p.

DAVID, M. Geostatistical ore reserve estimation. Amsterdam: Elsevier, 1977. 364p.

DETTINGER, M., WILSON, J. First-order analysis of uncertainty in ground water flow parameter: a geoestatistical approach. Water Resources Research, v. 15, n. 2, p. 269-280, 1981.

DOWD, P. A., MILTON, D. W. Geostatistical estimation of a section of the Perseverance nickel deposit. In: MATHERON, G., ARMSTRONG, M. (Eds.). Geostatistical case studies. Dordrecht: D. Reidel Pub. Co., 1987. 248p. cap. 3, p. 39-67.

JOURNEL, A.G., HUIJBREGTS, C.J. (Eds.). Mining geoestatistics. London: Academic Press, 1978. 600p.

KRIGE, D. G. Lognormal-de Wijsian Geostatistics for ore valuation, South African Institute of Mining and Metallurgy, 1978. (Monograph 1).

MASKEY, S., GUINOT, V. Improved first-order second moment method for uncertainty estimation in flood forecasting. Hydrological Sciences Journal, v. 48, n.2, p. 183-196, 2003.

ROSSI, M., DEUTSCH, C.V. (Eds.). Mineral resource estimation. Dordrecht: Springer, 2014. 332p.

SINCLAIR, A. J., BLACKWELL, G. H. Applied mineral inventory estimation. Cambridge: Cambridge University Press, 2002. 381p.

YAMAMOTO, J. K. An alternative measure of the reliability of ordinary kriging estimates. Mathematical Geology, v. 32, n. 4, p. 489-509, 2000.

YAMAMOTO, J. K., KIKUDA, A. T., RAMPAZZO, G. J., LEITE, C. B. B. Uncertainties associated with arithmetic map operations in GIS. In: ACADEMIA BRASILEIRA DE CIÊNCIAS, 2018. Anais...

Received: 9 October 2018 - Accepted: 14 March 2019. 